\title{
Resting Heart Rate and Long-Term Outcomes Among African Americans: Insights From the Jackson Heart Study
}

\author{
Kishan S. Parikh, MD, Melissa A. Greiner, MS, Takeki Suzuki, MD, PhD, Adam D. DeVore, \\ MD, Chad Blackshear, MS, Joseph F. Maher, MD, Lesley H. Curtis, PhD, Adrian F. \\ Hernandez, MD, MHS, Emily C. O'Brien, PhD, and Robert J. Mentz, MD \\ Duke Clinical Research Institute (Drs Parikh, DeVore, Curtis, Hernandez, O'Brien, and Mentz and \\ Ms Greiner) and Department of Medicine (Drs DeVore, Curtis, Hernandez, O'Brien, and Mentz), \\ Duke University School of Medicine, Durham, North Carolina; and Department of Medicine, \\ University of Mississippi School of Medicine (Drs Suzuki and Maher), and Center of Biostatistics \\ and Bioinformatics (Mr Blackshear), University of Mississippi Medical Center, Jackson, \\ Mississippi
}

\begin{abstract}
Importance-Increased resting heart rate is associated with worse outcomes in studies of mostly white populations, but its significance is not well established in African Americans whose cardiac comorbidities and structural abnormalities differ.
\end{abstract}

Objective-We studied the prognostic utility of heart rate in a community-based African American cohort in Jackson, Mississippi.

Design-We included 5261 participants in the Jackson Heart Study. Baseline heart rate was assessed by quintiles and as a continuous variable. Study follow-up was greater than 7 years and started in 2000 .

Setting-The Jackson Heart Study, a prospective, community-based study in Jackson, Mississippi.

Participants-All participants with baseline heart rate documented by 12-lead electrocardiogram without pacing or atrial fibrillation on their baseline Jackson Heart Study exam were included in our study.

\footnotetext{
Corresponding Author: Kishan S. Parikh, MD, Duke Clinical Research Institute, PO Box 17969, Durham, NC 27715; telephone: 919-668-7835; kishan.parikh@duke.edu.

Author Contributions: Dr Mentz had full access to all the data in the study and takes responsibility for the integrity of the data and the accuracy of the data analysis.

Conflict of Interest Disclosures: Dr DeVore reported receiving research funding from the American Heart Association, Amgen, and Novartis. Dr Hernandez reported receiving research support from Amgen, Bayer, Bristol Myers Squibb, GlaxoSmithKline, Merck, and Portola; and serving on advisory boards for Amgen, AstraZeneca, Bayer, Eli Lilly, Gilead, GlaxoSmithKline, Janssen, Merck, Novartis, Ortho-McNeil-Janssen, Pfizer, Pluristem, Sensible, and MyoKardia. Dr Mentz reported receiving research support from Amgen, AstraZeneca, Bristol-Myers Squibb, GlaxoSmithKline, Gilead, Novartis, Otsuka, and ResMed; honoraria from HeartWare, Janssen, Luitpold Pharmaceuticals, Novartis, ResMed, and Thoratec; and serving on advisory boards for Luitpold Pharmaceuticals. Dr O'Brien reported receiving research support from Bristol-Myers Squibb, GlaxoSmithKline, Janssen Scientific, Novartis, and Pfizer; and serving on an advisory board for Portola Pharmaceuticals. No other disclosures were reported.
}

Disclaimer: The views expressed in this manuscript are those of the authors and do not necessarily represent the views of the National Heart, Lung, and Blood Institute; the National Institutes of Health; or the U.S. Department of Health and Human Services. 
Main Outcomes and Measures-We estimated unadjusted and adjusted associations between heart rate and all-cause mortality and heart failure hospitalization using Cox proportional hazards models.

Results-Median baseline heart rate was 63 bpm (interquartile range, 57-71 bpm). The highest heart rate quintile (73-118 bpm) included more women, higher rates of diabetes and hypertension, higher body mass index, less average activity, and lower $\beta$-blocker use compared with lower quintiles. Caffeine intake and ejection fraction were similar between groups. As a continuous variable, elevated heart rate was associated with increased mortality and heart failure hospitalizations with adjusted hazard ratios for every $5 \mathrm{bpm}$ increase of 1.14 (95\% CI, 1.10-1.19) and 1.10 (95\% CI, 1.05-1.16), respectively. Similar patterns were observed in comparisons between highest and lowest quintiles.

Conclusions and Relevance-Higher baseline heart rate was associated with increased mortality and heart failure hospitalizations among African Americans in the Jackson Heart Study.

\section{Introduction}

Elevated resting heart rate is associated with poor outcomes in both healthy individuals 1,2 and patients with cardiovascular disease,,${ }^{3,4}$ possibly related to atherosclerosis, ${ }^{5}$ plaque rupture, ${ }^{6}$ arrhythmia, and ventricular systolic dysfunction in populations with elevated heart rate. Reduction of elevated heart rate is also a therapeutic goal in patients with myocardial infarction, heart failure, and angina pectoris. ${ }^{7}$ However, previous studies of the prognostic importance of heart rate either did not report participant race ${ }^{1,2}$ or included few African American participants (eg, 4\% of participants in the Systolic Heart Failure Treatment With the $\mathrm{I}_{\mathrm{f}}$ Inhibitor Ivabradine [SHIFT] trial were neither white nor Asian). ${ }^{8}$ Given that African Americans represent approximately $15 \%$ of the US population ${ }^{9}$ and have more hypertension, diabetes mellitus, coronary artery disease, and heart failure, ${ }^{10}$ there is an unmet need to characterize resting heart rate in African Americans as a prognostic factor and to inform future study design. We hypothesized that elevated resting heart rate would be associated with adverse outcomes in African American participants in a large community cohort study. We also aimed to identify factors associated with the development of elevated resting heart rate over time in an African American population.

\section{Methods}

\section{Data Sources}

The Jackson Heart Study is a prospective community-based observational study designed to assess determinants of cardiovascular disease in an African American population. ${ }^{11}$ Data collection began in 2000, and recruitment methods have been described in detail. ${ }^{12}$ In brief, subjects were recruited from the Jackson, Mississippi, cohort of the Atherosclerosis Risk in Communities (ARIC) study and from the overall tricounty population. Study visits have occurred 3 times since study initiation: exam 1 (September 2000-March 2004), exam 2 (October 2005-December 2008), and exam 3 (February 2009-January 2013). All participants provided written informed consent, and study protocols were approved by local institutional review boards. 
Available data include demographic characteristics, comorbid conditions, medications, laboratory values, supine 12-lead digital electrocardiograms (ECGs) at exams 1 and 3, and echocardiogram at exam $1 .{ }^{13}$ The ECGs were recorded after overnight fast and transmitted using the Marquette MAC/PC digital ECG recorder (Marquette Electronics) to the Electrocardiographic Reading Center at the University of Minnesota. ECGs were then read using a computer algorithm developed using the Minnesota Code Modular ECG Analysis System developed for clinical trials and population studies and validated previously. ${ }^{13}$ Resting heart rates were obtained from the ECGs and underwent review by a physician if the reported heart rate was $40 \mathrm{bpm}$ or less or $150 \mathrm{bpm}$ or greater or was accompanied by abnormal rhythm.

\section{Study Population}

For analysis of the primary end point of mortality, we created a cohort (Cohort A) of all patients with exam 1 documentation of heart rate on ECG. Patients with atrial or ventricular pacing at exam 1 as indicated by ECG atrioventricular Minnesota Code 6-8 or atrial fibrillation were excluded from the analysis. ${ }^{13}$ Secondary end point analyses were conducted in the following subgroups of Cohort A: (1) For the analysis of heart failure hospitalization, we included participants surviving to 2005 , when heart failure hospitalization surveillance began (Cohort B); (2) for the analysis of factors associated with elevated heart rate, we included participants who completed exam 3 and had documentation of heart rate on ECG at this follow-up (Cohort C).

\section{Outcomes}

The primary outcome was all-cause mortality within 9 years after exam 1 . Procedures to identify deaths in the Jackson Heart Study have been described previously. ${ }^{14}$ In summary, data were generated from the following sources: annual follow-up, including interviews with participants and next of kin; the National Death Index from the Centers for Disease Control and Prevention; and physician and coroner reports reviewed by a medical record abstraction unit. All diagnoses were adjudicated by trained medical staff.

We also assessed the cumulative incidence of heart failure hospitalization between 2005 and 2011 among participants who survived to January 1, 2005 (when surveillance for heart failure hospitalizations began) for participants in Cohort B. Heart failure hospitalizations were adjudicated by trained and certified heart failure abstractors through December 31, 2011, at the time of the analysis and required (1) a discharge diagnosis of International Classification of Diseases, Ninth Revision, Clinical Modification (ICD-9-CM) code 428 and/or underlying cause of death I50; and (2) radiographic, hemodynamic, or ECG findings of heart failure; or (3) autopsy finding of pulmonary edema or heart failure. ${ }^{14}$ Any heart failure hospitalization occurring in a non-catchment area hospital was validated with additional data after participant consent. Trained medical staff also reviewed and adjudicated primary diagnoses by their corresponding ICD-9-CM codes. Finally, elevated heart rate during study follow-up, defined as a heart rate increase of $5 \mathrm{bpm}$ or greater between exam 1 and exam 3, was assessed as a secondary outcome among participants in Cohort C. 


\section{Covariates}

Baseline variables obtained from exam 1 were demographic characteristics, comorbid conditions, self-reported physical activity and caffeine consumption, physical examination findings, laboratory values, echocardiographic and ECG results, and medications. Among comorbid conditions, hypertension (140/90 mm Hg or greater or use of blood pressure lowering medications) and diabetes mellitus (fasting glucose of $126 \mathrm{mg} / \mathrm{dL}$ or greater, hemoglobin A1c of $6.5 \%$ or greater, or taking diabetes medications) were based on physician examination or laboratory values; atrial fibrillation was based on electrocardiographic evidence; and myocardial infarction, stroke, chronic lung disease and smoking were self-reported. To determine the presence of heart failure at baseline, we applied modified Gothenburg criteria as developed and validated in the ARIC study. ${ }^{15}$ To ascertain left ventricular hypertrophy, we used quantitative left ventricular mass measurement from 2-D or M-mode echocardiography when available (missing for 5\% of participants); otherwise, left ventricular hypertrophy was based on a qualitative assessment of mild, moderate, or severe hypertrophy, as described previously. ${ }^{13}$ Baseline medication variables were ascertained using therapeutic classification codes recorded based on medications taken within 2 weeks of exam 1 .

\section{Statistical Analysis}

We described exam 1 baseline characteristics of the study population by heart rate quintiles using frequencies with percentages for categorical variables and means with SDs or medians with interquartile ranges (IQRs) for continuous variables. We tested for differences between groups using $\chi^{2}$ tests for categorical variables and Kruskal-Wallis tests for continuous variables.

We assessed outcomes of interest using heart rate as both a categorical variable and a continuous variable. As a categorical variable, we calculated the cumulative incidence of allcause mortality (Cohort A) and heart failure hospitalization (Cohort B) by heart rate quintile using Kaplan-Meier estimates and tested for differences between the groups using log-rank tests. We estimated the unadjusted and adjusted associations between heart rate quintile and mortality and heart failure hospitalization outcomes using Cox proportional hazards models. As a continuous variable, we assessed the association of heart rate per $5 \mathrm{bpm}$ increments with all-cause mortality and heart failure hospitalization. Covariates from the baseline exam used as adjustment variables in the models were derived from previous heart rate studies $^{1-3,5,7}$ and clinical judgment (age, sex, prior myocardial infarction, heart failure, hypertension, stroke, diabetes, lung disease, current smoking, prior smoking, alcoholic drinks/week, physical activity hours/week, caffeine mg/day, body mass index, neck circumference, systolic blood pressure, sodium, estimated glomerular filtration rate, hemoglobin, ejection fraction, left ventricular hypertrophy, left ventricular dimension, left bundle branch block, right bundle branch block, QRS duration, angiotensin-converting enzyme (ACE) inhibitor/angiotensin II receptor blocker (ARB), antiarrhythmic medication, anti-platelet medication, $\beta$-blocker, calcium channel blocker, digoxin, diuretic, and statin). Data were censored for study participants at the time of (a) participant loss to follow-up or (b) end of study event surveillance follow-up on December 31, 2011. For heart failure hospitalization, we also censored data for participants at the time of death. 
For all outcomes, we first tested for multicollinearity using the variance inflation factor of covariates and removed variables when this value exceeded 3 . We also tested the linearity of continuous heart rate functional form using Box-Tidwell and supremum tests and explored polynomials and restricted cubic splines as indicated. We used Cox model estimates from the adjusted continuous heart rate models to calculate and plot adjusted outcome rates by continuous heart rate with other covariates standardized to the mean. We performed an additional sensitivity analysis excluding participants with any electrocardiographic evidence of arrhythmia (including atrial fibrillation), prior myocardial infarction, or taking nodal agents (ie, $\beta$-blocker, calcium channel blocker, digoxin) or antiarrhythmic agents at exam 1.

To examine the development of elevated heart rate compared to stable or reduced heart rate in Cohort $\mathrm{C}$, we used a modified Poisson model with an offset parameter to adjust for log of participant time between exam 1 and exam 3 (range, 6-12 years). ${ }^{16,17}$ An increase in heart rate was defined as a greater than $5 \mathrm{bpm}$ increase from baseline to follow-up, given clinical relevance and preliminary examination of heart rate change distribution data. We used clinical judgment to select variables for the prediction model. As a sensitivity analysis, we changed the threshold to a greater than $10 \mathrm{bpm}$ increase from baseline and repeated the analysis.

Most variables had very low missing rates. For variables with less than 5\% missing data, we imputed continuous variables to the overall median value, dichotomous variables to no, and multichotomous variables to the most frequent categorical value. ${ }^{18}$ For medication variables that were missing in $7 \%$ of participants, we assigned missing values to a separate category (coded as no, yes, or missing). We used a 2-tailed $a=.05$ to establish statistical significance and report 95\% CIs. We used SAS version 9.4 (SAS Institute Inc) for all analyses. The institutional review board of the Duke University Health System approved the study.

\section{Results}

Exam 1 was completed by 5301 participants. Figure 1 shows the derivation of the survival analysis cohort, Cohort A $(\mathrm{n}=5261)$; the heart failure hospitalization analysis cohort, Cohort B $(n=5156)$, and the heart rate change analysis cohort, Cohort C $(n=3699)$. The overall median heart rate at baseline was $63 \mathrm{bpm}$ (IQR, 57-71 bpm). Participants in the highest heart rate quintile (73-118 bpm) included more women and had higher rates of heart failure, diabetes, hypertension, and chronic lung disease (Table 1). Participants in the highest quintile were also more likely to have higher body mass index, to have less self-reported physical activity, and to have lower $\beta$-blocker use than other groups. For participants in Cohort A, median follow-up was 8.9 years (IQR, 8.1-9.7) and 510 participants (9.7\%) died. Median follow-up for participants in Cohort B was 7.0 years (IQR, 7.0-7.0) and 329 participants $(6.4 \%)$ experienced a heart failure hospitalization (eTable 1).

Table 2 shows the risks for death and heart failure hospitalization by heart rate quintile and per $5 \mathrm{bpm}$ increase. Participants in the highest quintile had increased mortality risk over the 9-year follow-up period before and after adjustment (eTable 1; Figure 2). After adjustment, every $5 \mathrm{bpm}$ increase in heart rate was associated with a $14 \%$ increase in the hazard of mortality (Figure 2). Elevated resting heart rate was associated with higher risk of heart 
failure hospitalization through 7 years of follow-up (eTable 1; Figure 2). Box-Tidwell, supremum, and spline tests indicated linear functional form for continuous heart rate in both mortality and heart failure hospitalization models. Sensitivity analysis for participants without arrhythmias (including atrial fibrillation), prior myocardial infarction, nodal and antiarrhythmic agents at baseline revealed consistent findings for the association between heart rate and risk for all-cause mortality. Although the unadjusted results and the direction of the association persisted in the heart failure hospitalization sensitivity analysis, the analysis was underpowered ( $\mathrm{n}=116$ events) and the adjusted associations were not statistically significant (eTables 2 and 3).

Among the cohort of patients who completed exam 1 and exam 3 (median time interval, 8 years; IQR, 7.4-8.4), patients most frequently did not have a change in heart rate, whereas $974(26.3 \%)$ and $453(12.2 \%)$ experienced heart rate increases of greater than $5 \mathrm{bpm}$ and greater than $10 \mathrm{bpm}$, respectively (eFigure). Variables potentially affecting heart rate change were also assessed for this cohort. Diabetes, current smoking, and left bundle-branch block were associated with an increase in resting heart rate of $5 \mathrm{bpm}$ after adjustment (Table 3). $\beta$ Blocker therapy was not associated with a lower risk of elevated heart rate. In the sensitivity analysis (greater than $10 \mathrm{bpm}$ ), adjusted risk ratios for diabetes and smoking were even higher, but there was no statistically significant association with left bundle-branch block (eTable 4).

\section{Discussion}

We found a stepwise increase in the risk of all-cause mortality per quintile of baseline heart rate among Jackson Heart Study participants. Participants with resting heart rate greater than $73 \mathrm{bpm}$ had a greater than twofold higher risk for mortality over 9 years, compared with participants in the lowest quintile, with higher cumulative incidence of death observed throughout the follow-up period. Elevated heart rate at baseline was also a risk factor for heart failure hospitalization when assessed as both a categorical variable and a continuous variable. Participants with diabetes and current smokers were at highest risk for developing elevated heart rate.

Consideration of elevated heart rate as a therapeutic target has gained attention recently for patients with heart failure, ${ }^{19}$ and our results have important implications for African American patients with heart failure. African American participants in the ARIC study are more likely than white participants to develop heart failure (9.1 per 1000 person-years vs 6.0 per 1000 person-years among men; 8.1 vs 3.4 among women), and their disease is associated with worse morbidity and mortality, including $45 \%$ greater risk of death or functional decline. ${ }^{20}$ In addition, when adequately represented in corresponding trials, African Americans have responded differently to heart failure medications, including enalapril, ${ }^{21}$ hydralazine and isosorbide dinitrate combination, ${ }^{22}$ and the $\beta$-blocker bucindolol. ${ }^{23,}{ }^{24}$ Our study expands upon current understanding of phenotypic similarities and differences among patients with heart failure.

To our knowledge, ours is the largest report identifying elevated resting heart rate as a risk factor for adverse outcomes among African Americans. Our results extend the findings of 
previous studies that consistently identified elevated resting heart rate as a risk factor for allcause mortality and heart failure hospitalizations in predominantly white populations. , $^{4,25-28}$ Our findings also support those of the Multi-Ethnic Study of Atherosclerosis (28\% African American population), which associated elevated resting heart rate with risk for incident heart failure. ${ }^{29}$ Our analysis of heart rate as a continuous variable revealed a linear association with mortality risk in. In contrast, a threshold effect for increased risk for patients with resting heart rate greater than 70 to $75 \mathrm{bpm}$ has been noted in previous studies for the general population and for patients with heart failure. ${ }^{26-28}$

Participants with higher resting heart rate were more likely to be women, to be physically inactive and obese, and to have diabetes and cardiovascular comorbid conditions. These participants were more likely to have heart failure and to receive heart failure therapies, including ACE inhibitors or ARBs and diuretics, but less likely to receive $\beta$-blockers.

Several hypotheses have been proposed to explain the link between heart rate and survival. Development of myocardial energy depletion, ischemia, calcium dysregulation is associated with tachycardia-mediated cardiomyopathy and may contribute to heart failure. ${ }^{30}$ Underlying autonomic dysfunction and vagal or sympathetic tone imbalance marked by elevated heart rate may also negatively affect health., $, 7,31$ Finally, although the prognostic value of heart rate in our cohort was statistically significant after adjustment for comorbid conditions, several conditions, including lung disease, renal disease, coronary artery disease, and heart failure, were associated with elevated resting heart rate. ${ }^{32,33}$

Change in heart rate between exam 1 and exam 3 appeared to follow a roughly normal distribution with little change over time in our community-based cohort. We identified factors associated with elevated heart rate, which has previously been associated with risk for all-cause mortality in a large heart failure cohort. ${ }^{34}$ Surprisingly, age at baseline was not associated with heart rate changes, perhaps due to follow-up duration. Participants with diabetes and current smokers were at high risk for an increase of greater than $5 \mathrm{bpm}$ and greater than $10 \mathrm{bpm}$. Elevated heart rate in these populations may be a marker for associated coronary atherosclerotic changes or autonomic dysfunction for which they are at heightened risk. ${ }^{5}{ }^{6}$ Elevated baseline heart rate was associated with a lower risk for developing elevated heart rate over time, which may be explained by regression to the mean and interim nonfatal events. The use of $\beta$-blockers at baseline and more daily physical activity had a nonsignificant relationship with elevated heart rate after adjustment.

\section{Clinical Implications}

African American patients presenting with higher resting heart rate are at increased risk for long-term adverse outcomes including all-cause mortality and heart failure hospitalization. Increased heart rate is associated with smoking and diabetes, and further study is needed to understand factors contributing to its development.

\section{Limitations}

This was a retrospective analysis from an observational cohort study, and our findings are therefore limited to associations. We adjusted for covariates in our analyses, but many of them were obtained by self-report of participants. Also, although obtained using a well- 
validated digital ECG algorithm and with physician oversight to ensure accuracy, our resting heart rate values were derived from a single ECG at baseline. Our analysis therefore does not reflect day to day variations in heart rate or heart rate response to physical exertion, which may also reveal additional insight into the relationship between heart rate and clinical outcomes. Although a strength to have ECG assessed at 2 time points (exams 1 and 3), ECG was not performed at exam 2 and limited additional risk assessment for mortality and heart failure hospitalization. The analysis for heart failure hospitalization risk was limited by lack of heart failure event collection until 2005, potentially leading to an underestimated prognostic value of heart rate. The analysis of predictors of increased heart rate change was limited by $18 \%$ of participants who were alive but did not complete exam 3 .

\section{Conclusions}

Elevated resting heart rate was associated with greater risk for mortality and heart failure hospitalization among African Americans in a large community-based cohort. Participants with diabetes and smokers were most likely to develop elevated resting heart rate over time.

\section{Supplementary Material}

Refer to Web version on PubMed Central for supplementary material.

\section{Acknowledgments}

Funding/Support: The Jackson Heart Study is supported by contracts HHSN268201300046C, HHSN268201300047C, HHSN268201300048C, HHSN268201300049C, and HHSN268201300050C from the National Heart, Lung, and Blood Institute and the National Institute on Minority Health and Health Disparities. This study was supported by grant R01HL117305 from the National Heart, Lung, And Blood Institute and grant 5T32GM086330-05 from the National Institute of General Medical Sciences.

Role of the Sponsors: The funding agencies were not directly involved in the design and conduct of the study; collection, management, analysis, and interpretation of the data; preparation, review, or approval of the manuscript; or the decision to submit the manuscript for publication.

\section{References}

1. Jouven X, Empana JP, Schwartz PJ, Desnos M, Courbon D, Ducimetiere P. Heart-rate profile during exercise as a predictor of sudden death. N Engl J Med. 2005; 352(19):1951-1958. [PubMed: 15888695]

2. Kannel WB, Kannel C, Paffenbarger RS Jr, Cupples LA. Heart rate and cardiovascular mortality: the Framingham Study. Am Heart J. 1987; 113(6):1489-1494. [PubMed: 3591616]

3. Diaz A, Bourassa MG, Guertin MC, Tardif JC. Long-term prognostic value of resting heart rate in patients with suspected or proven coronary artery disease. Eur Heart J. 2005; 26(10):967-974. [PubMed: 15774493]

4. Zhang D, Shen X, Qi X. Resting heart rate and all-cause and cardiovascular mortality in the general population: a meta-analysis. CMAJ. 2016; 188(3):E53-E63. [PubMed: 26598376]

5. Giannoglou GD, Chatzizisis YS, Zamboulis C, Parcharidis GE, Mikhailidis DP, Louridas GE. Elevated heart rate and atherosclerosis: an overview of the pathogenetic mechanisms. Int J Cardiol. 2008; 126(3):302-312. [PubMed: 18068835]

6. Heidland UE, Strauer BE. Left ventricular muscle mass and elevated heart rate are associated with coronary plaque disruption. Circulation. 2001; 104(13):1477-1482. [PubMed: 11571239]

7. Fox K, Borer JS, Camm AJ, et al. Resting heart rate in cardiovascular disease. J Am Coll Cardiol. 2007; 50(9):823-830. [PubMed: 17719466] 
8. Bohm M, Swedberg K, Komajda M, et al. Heart rate as a risk factor in chronic heart failure (SHIFT): the association between heart rate and outcomes in a randomised placebo-controlled trial. Lancet. 2010; 376(9744):886-894. [PubMed: 20801495]

9. US Census Bureau. [Accessed November 18, 2015] State and County QuickFacts. 2015. http:// quickfacts.census.gov

10. Bui AL, Horwich TB, Fonarow GC. Epidemiology and risk profile of heart failure. Nat Rev Cardiol. 2011; 8(1):30-41. [PubMed: 21060326]

11. Taylor HA Jr. The Jackson Heart Study: an overview. Ethn Dis. 2005; 15(4 Suppl 6):S6-1-3.

12. Fuqua SR, Wyatt SB, Andrew ME, et al. Recruiting African-American research participation in the Jackson Heart Study: methods, response rates, and sample description. Ethn Dis. 2005; 15(4 Suppl 6):S6-18-29.

13. Carpenter MA, Crow R, Steffes M, et al. Laboratory, reading center, and coordinating center data management methods in the Jackson Heart Study. Am J Med Sci. 2004; 328(3):131-144. [PubMed: 15367870]

14. Keku E, Rosamond W, Taylor HA Jr, et al. Cardiovascular disease event classification in the Jackson Heart Study: methods and procedures. Ethn Dis. 2005; 15(4 Suppl 6):S6-62-70.

15. Avery CL, Mills KT, Chambless LE, et al. Long-term association between self-reported signs and symptoms and heart failure hospitalizations: the Atherosclerosis Risk In Communities (ARIC) Study. Eur J Heart Fail. 2010; 12(3):232-238. [PubMed: 20097681]

16. Breslow NE, Day NE. Statistical methods in cancer research. Volume II--The design and analysis of cohort studies. IARC Sci Publ. 1987; (82):1-406.

17. Zou G. A modified Poisson regression approach to prospective studies with binary data. Am J Epidemiol. 2004; 159(7):702-706. [PubMed: 15033648]

18. Harrell, FE. Regression modeling strategies : with applications to linear models, logistic regression, and survival analysis. New York: Springer; 2001.

19. Swedberg K, Komajda M, Bohm M, et al. Ivabradine and outcomes in chronic heart failure (SHIFT): a randomised placebo-controlled study. Lancet. 2010; 376(9744):875-885. [PubMed: 20801500]

20. Go AS, Mozaffarian D, Roger VL, et al. Heart disease and stroke statistics--2014 update: a report from the American Heart Association. Circulation. 2014; 129(3):e28-e292. [PubMed: 24352519]

21. Exner DV, Dries DL, Domanski MJ, Cohn JN. Lesser response to angiotensin-converting-enzyme inhibitor therapy in black as compared with white patients with left ventricular dysfunction. $\mathrm{N}$ Engl J Med. 2001; 344(18):1351-1357. [PubMed: 11333991]

22. Carson P, Ziesche S, Johnson G, Cohn JN. Racial differences in response to therapy for heart failure: analysis of the Vasodilator-Heart Failure Trials. Vasodilator-Heart Failure Trial Study Group. J Card Fail. 1999; 5(3):178-187. [PubMed: 10496190]

23. Beta-Blocker Evaluation of Survival Trial I. A trial of the beta-blocker bucindolol in patients with advanced chronic heart failure. N Engl J Med. 2001; 344(22):1659-1667. [PubMed: 11386264]

24. Ishizawar D, Yancy C. Racial differences in heart failure therapeutics. Heart Fail Clin. 2010; 6(1): 65-74. [PubMed: 19945062]

25. Greene SJ, Vaduganathan M, Wilcox JE, et al. The prognostic significance of heart rate in patients hospitalized for heart failure with reduced ejection fraction in sinus rhythm: insights from the EVEREST (Efficacy of Vasopressin Antagonism in Heart Failure: Outcome Study With Tolvaptan) trial. JACC Heart Fail. 2013; 1(6):488-496. [PubMed: 24622000]

26. Ho JE, Larson MG, Ghorbani A, et al. Long-term cardiovascular risks associated with an elevated heart rate: the Framingham Heart Study. J Am Heart Assoc. 2014; 3(3):e000668. [PubMed: 24811610]

27. Khan H, Kunutsor S, Kalogeropoulos AP, et al. Resting heart rate and risk of incident heart failure: three prospective cohort studies and a systematic meta-analysis. J Am Heart Assoc. 2015; 4(1):e001364. [PubMed: 25589535]

28. Laskey WK, Alomari I, Cox M, et al. Heart rate at hospital discharge in patients with heart failure is associated with mortality and rehospitalization. J Am Heart Assoc. 2015; 4(4) 
29. Opdahl A, Ambale Venkatesh B, Fernandes VR, et al. Resting heart rate as predictor for left ventricular dysfunction and heart failure: MESA (Multi-Ethnic Study of Atherosclerosis). J Am Coll Cardiol. 2014; 63(12):1182-1189. [PubMed: 24412444]

30. Shinbane JS, Wood MA, Jensen DN, Ellenbogen KA, Fitzpatrick AP, Scheinman MM.

Tachycardia-induced cardiomyopathy: a review of animal models and clinical studies. J Am Coll Cardiol. 1997; 29(4):709-715. [PubMed: 9091514]

31. Palatini P. Heart rate as a cardiovascular risk factor: Do women differ from men? Ann Med. 2001; 33(4):213-221. [PubMed: 11405541]

32. Bohm M, Reil JC, Deedwania P, Kim JB, Borer JS. Resting heart rate: risk indicator and emerging risk factor in cardiovascular disease. Am J Med. 2015; 128(3):219-228. [PubMed: 25447617]

33. Bohm M, Schumacher H, Schmieder RE, et al. Resting heart rate is associated with renal disease outcomes in patients with vascular disease: results of the ONTARGET and TRANSCEND studies. J Intern Med. 2015; 278(1):38-49. [PubMed: 25431275]

34. Vazir A, Claggett B, Jhund P, et al. Prognostic importance of temporal changes in resting heart rate in heart failure patients: an analysis of the CHARM program. Eur Heart J. 2015; 36(11):669-675. [PubMed: 25368202] 


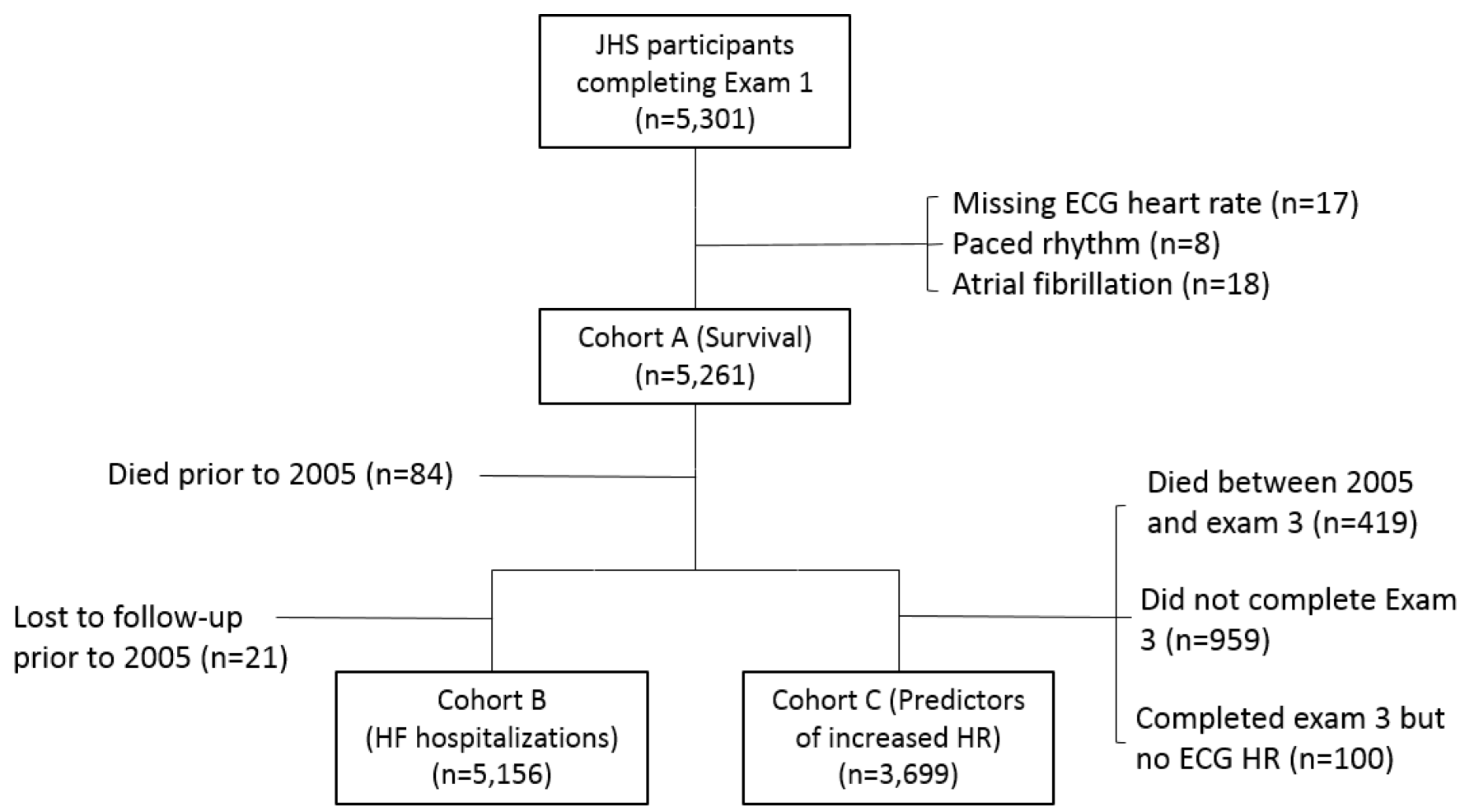

Figure 1.

Derivation of the Study Cohorts 


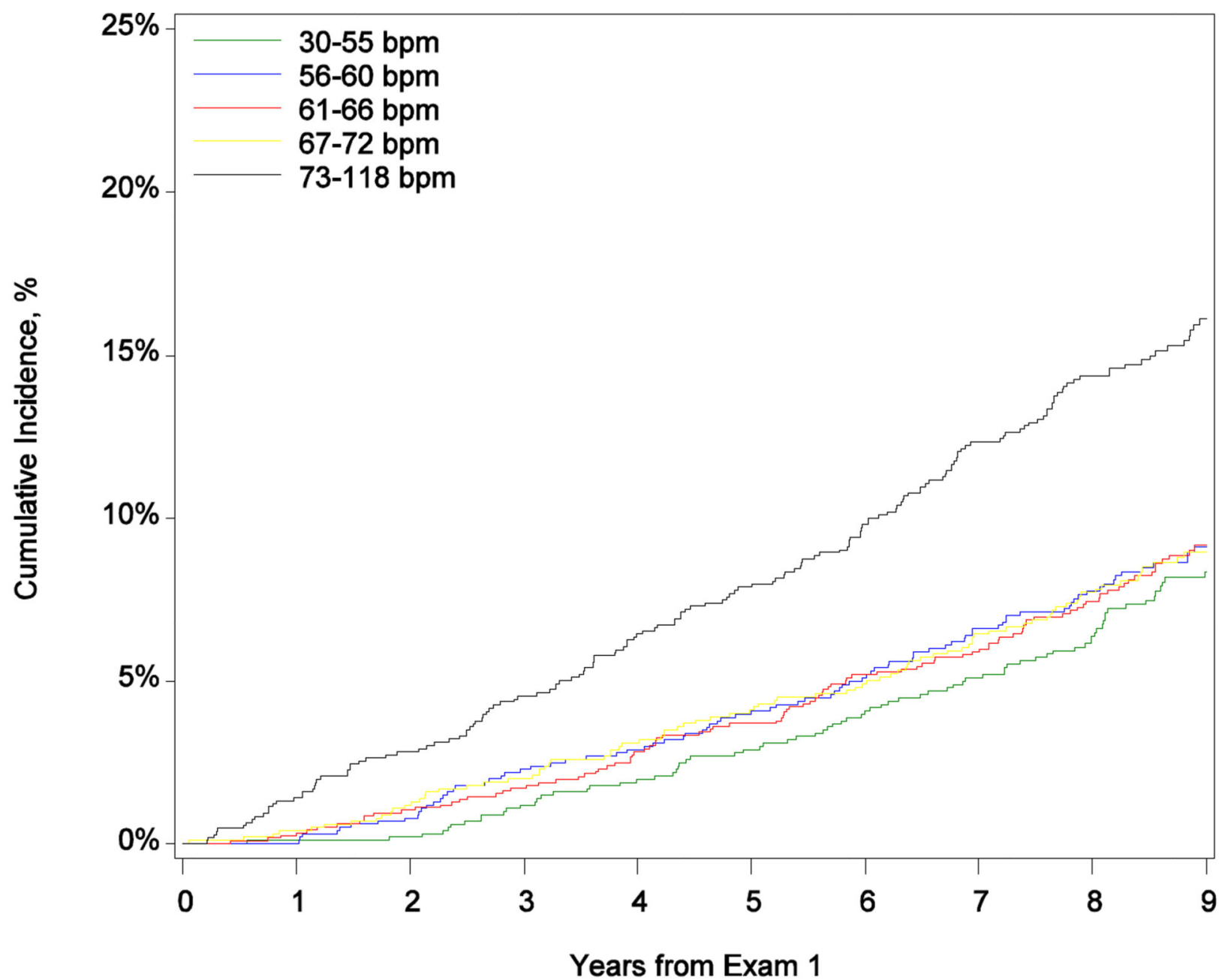

\begin{tabular}{|l|l|l|l|l|l|l|l|l|l|l|}
\hline $\begin{array}{c}\text { Heart Rate } \\
\text { Quintile }\end{array}$ & \multicolumn{10}{|c|}{ No. at Risk } \\
\hline & 0 & 1 & \multicolumn{1}{|c|}{2} & 3 & 4 & \multicolumn{1}{c|}{5} & 6 & 7 & 8 & 9 \\
\hline $30-55 \mathrm{bpm}$ & 1010 & 1008 & 1006 & 996 & 987 & 973 & 954 & 934 & 814 & 525 \\
\hline $56-60 \mathrm{bpm}$ & 1006 & 1006 & 998 & 983 & 977 & 961 & 946 & 921 & 812 & 525 \\
\hline $61-66 \mathrm{bpm}$ & 1173 & 1168 & 1154 & 1146 & 1132 & 1111 & 1079 & 1056 & 910 & 553 \\
\hline $67-72 \mathrm{bpm}$ & 1009 & 1002 & 993 & 984 & 969 & 953 & 933 & 912 & 776 & 498 \\
\hline $73-118 \mathrm{bpm}$ & 1063 & 1048 & 1028 & 1006 & 984 & 961 & 933 & 892 & 755 & 452 \\
\hline
\end{tabular}




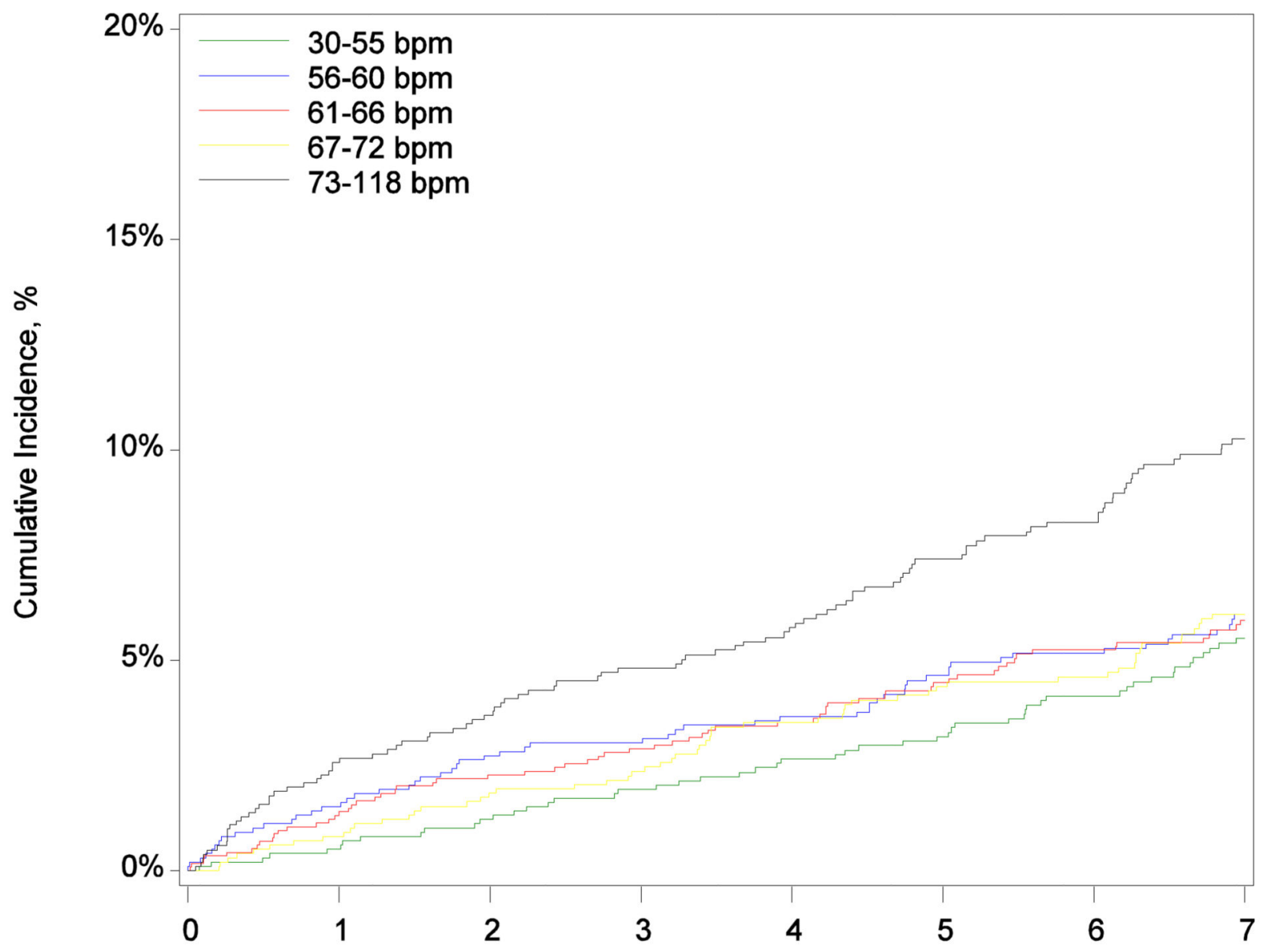

Years from 2005

\begin{tabular}{|l|l|l|l|l|l|l|l|l|}
\hline $\begin{array}{c}\text { Heart Rate } \\
\text { Quintile }\end{array}$ & \multicolumn{1}{|c|}{ No. at Risk } \\
\hline & \multicolumn{1}{|c|}{0} & \multicolumn{1}{|c|}{1} & 2 & 3 & 4 & 5 & 6 & 7 \\
\hline $30-55 \mathrm{bpm}$ & 1000 & 987 & 974 & 952 & 926 & 907 & 867 & 800 \\
\hline $56-60 \mathrm{bpm}$ & 993 & 973 & 952 & 938 & 917 & 885 & 861 & 799 \\
\hline $61-66 \mathrm{bpm}$ & 1155 & 1129 & 1104 & 1080 & 1042 & 1007 & 969 & 901 \\
\hline $67-72 \mathrm{bpm}$ & 988 & 974 & 953 & 934 & 901 & 872 & 850 & 779 \\
\hline $73-118 \mathrm{bpm}$ & 1020 & 973 & 947 & 919 & 878 & 844 & 809 & 720 \\
\hline
\end{tabular}




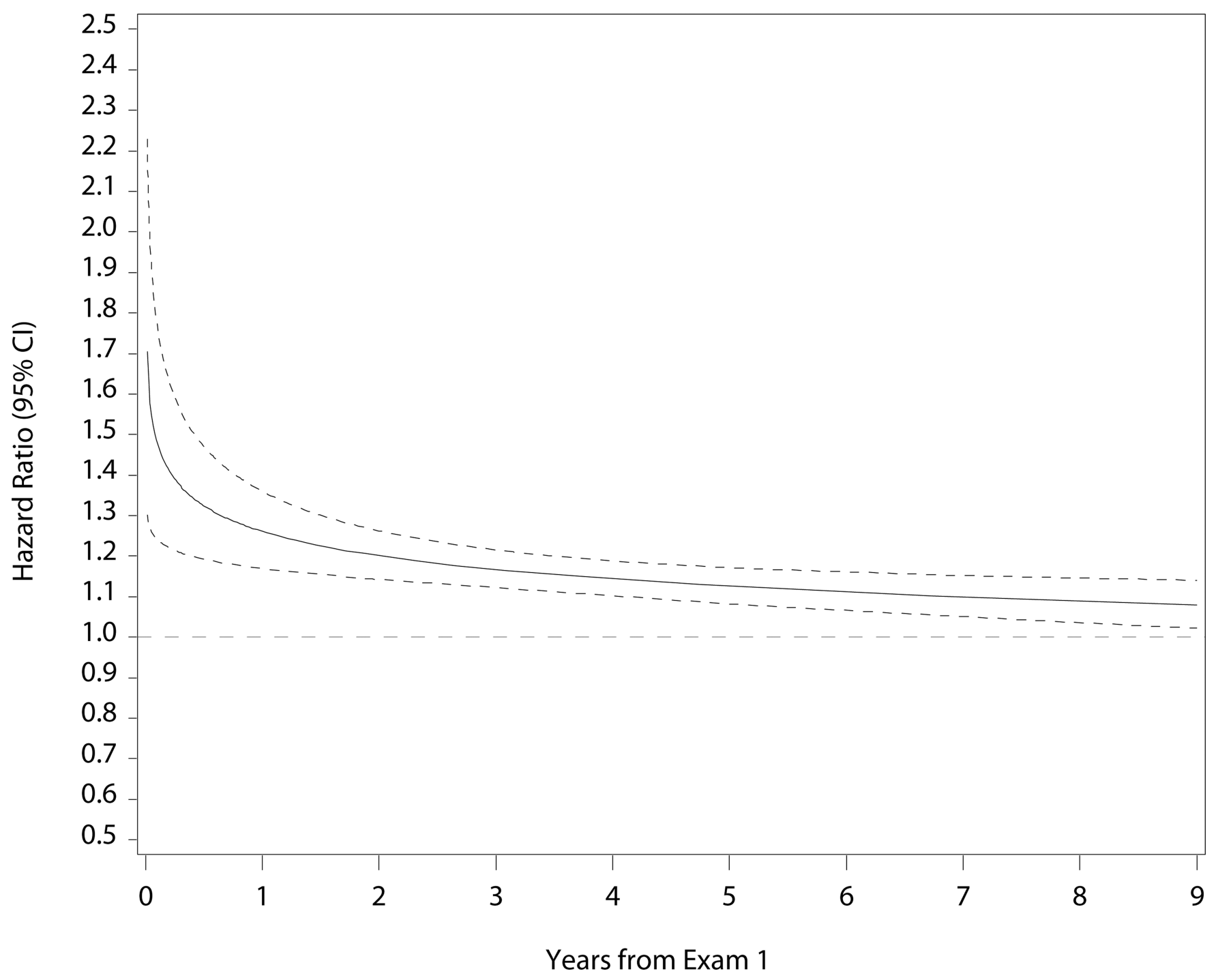

JAMA Cardiol. Author manuscript; available in PMC 2017 February 16. 


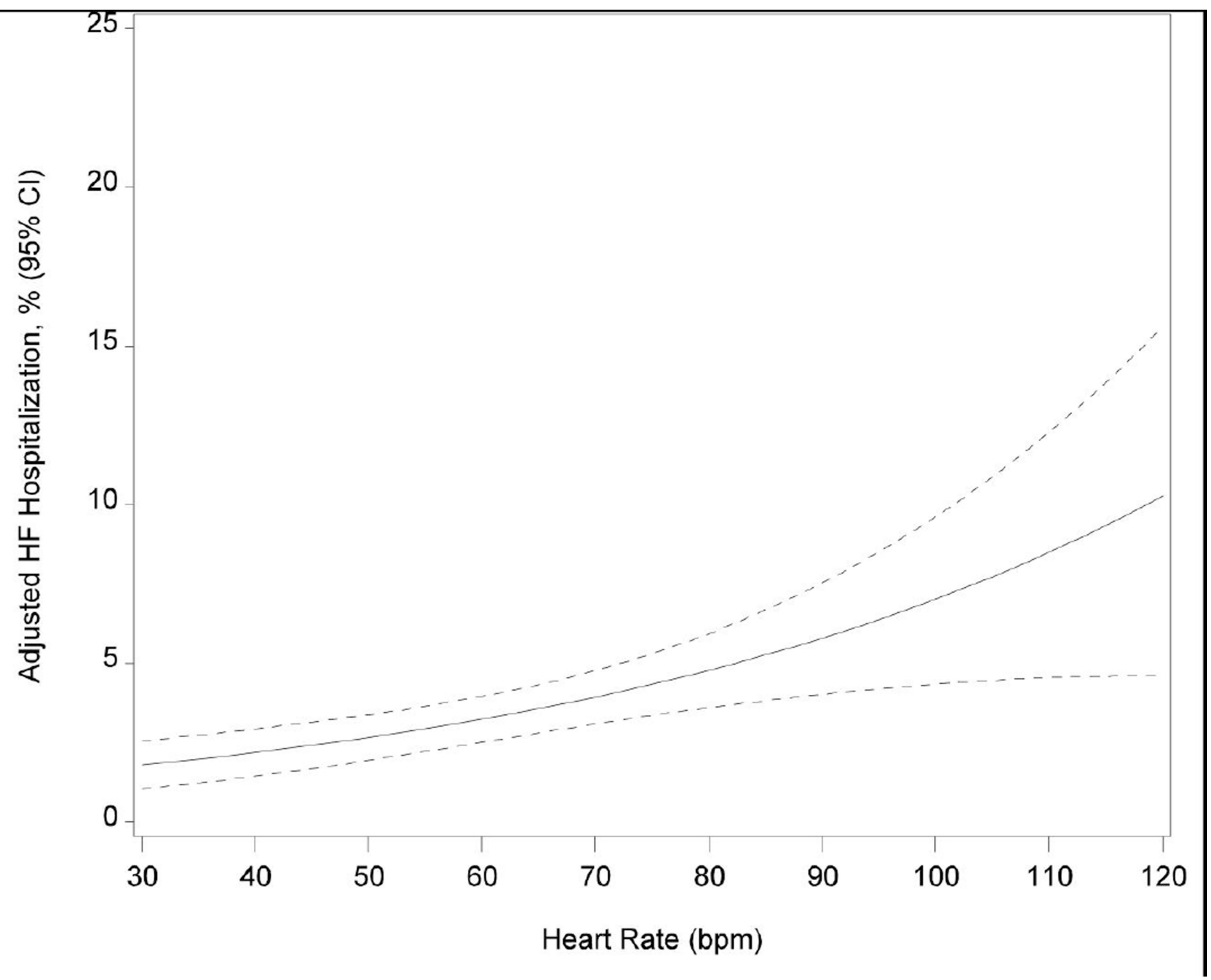

Figure 2.

Cumulative Incidence of Mortality (Panel A) and Heart Failure Hospitalization (Panel B) by Quintile of Baseline Heart Rate; and Adjusted Risk of Mortality (Panel C) and Heart Failure Hospitalization (Panel D) by Continuous Heart Rate 


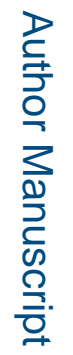

\begin{tabular}{|c|c|c|c|c|c|c|c|c|c|c|c|c|c|c|c|c|c|c|c|c|c|c|}
\hline 2 & & $\overline{8}$ & $\vec{z}_{\dot{v}}$ & $\bar{z}$ & $\begin{array}{l}\bar{\delta} \\
v \\
v\end{array}$ & $\begin{array}{l}\overline{8} \\
\dot{v}\end{array}$ & $\begin{array}{l}\overrightarrow{8} \\
v \\
v\end{array}$ & aे. & $:$ & $\infty$ & $\because$ & $\overline{\mathbf{s}}$ & $\begin{array}{l}\bar{\delta} \\
\dot{v}\end{array}$ & $\stackrel{\infty}{\stackrel{4}{\varphi}}$ & 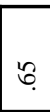 & $\begin{array}{l}\infty \\
0 \\
0\end{array}$ & $\overline{0}$. & $\stackrel{0}{0}$ & $\tilde{n}$ & $\begin{array}{l}\vec{\delta} \\
\dot{v}\end{array}$ & $\begin{array}{l}\bar{\delta} \\
\dot{v}\end{array}$ & $\bar{\sigma}$ \\
\hline \multirow{5}{*}{ 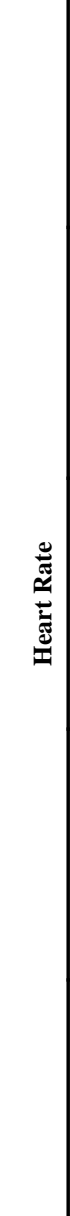 } & 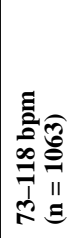 & 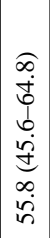 & $\begin{array}{l}\text { iे } \\
\text { ri }\end{array}$ & $\stackrel{m}{\varrho}$ & $\underset{m}{\dot{m}}$ & $\stackrel{9}{=}$ & $\overline{8}$ & $\stackrel{0}{0}$ & $\stackrel{+}{+}$ & $\stackrel{+}{\stackrel{m}{2}}$ & \begin{tabular}{|l|}
$\infty$ \\
$\stackrel{2}{2}$
\end{tabular} & & $\begin{array}{l}\infty \\
i \\
i\end{array}$ & $\vec{a}$ & ڤे & $\mid$\begin{tabular}{l}
0 \\
\hdashline
\end{tabular} & $\stackrel{i}{i}$ & $\begin{array}{l}\infty \\
\infty \\
\infty\end{array} \mid$ & 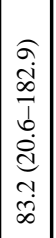 & 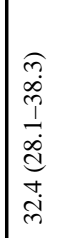 & 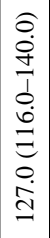 & 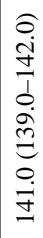 \\
\hline & 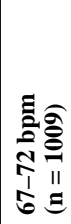 & 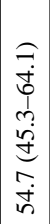 & $\stackrel{i}{\dot{m}}$ & $?$ & $\stackrel{+}{\mathrm{i}}$ & $\stackrel{i}{r}$ & $\overline{8}$ & $\overrightarrow{\dot{m}}$ & $\vec{n}$ & $\stackrel{m}{\stackrel{m}{2}}$ & $\underline{6}$ & & $\begin{array}{l}m \\
\dot{n}\end{array}$ & $\stackrel{+}{=}$ & $\stackrel{.}{\dot{\sigma}}$ & $\mid$\begin{tabular}{c|}
2 \\
$\infty$ \\
$\infty$
\end{tabular} & $\stackrel{+}{+}$ & $\dot{a}$ & 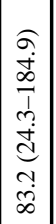 & 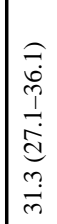 & 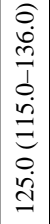 & 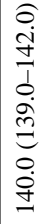 \\
\hline & 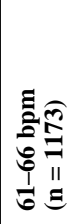 & 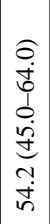 & 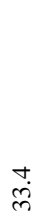 & $\hat{\sigma}$ & \begin{tabular}{|l|}
0 \\
$\stackrel{\infty}{-}$ \\
-1
\end{tabular} & $\ddot{0}$ & ì & $\stackrel{\vec{f}}{1}$ & 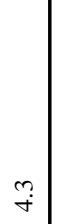 & $\overrightarrow{\mathrm{I}}$ & \begin{tabular}{|l|}
0 \\
$\infty$ \\
0 \\
-
\end{tabular} & & $\begin{array}{l}\infty \\
\dot{g} \\
\dot{q}\end{array}$ & $\stackrel{\infty}{=}$ & ?2. & $\because$ & $\begin{array}{l}0 \\
\dot{0}\end{array}$ & $\stackrel{?}{=}$ & 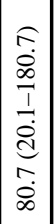 & 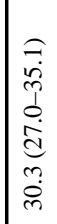 & 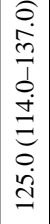 & 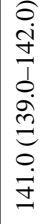 \\
\hline & 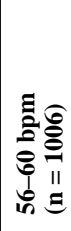 & 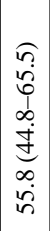 & $\hat{\dot{q}}$ & $\stackrel{0}{0}$ & $\underline{6}$ & $\stackrel{m}{n}$ & $\stackrel{m}{i}$ & $\vec{b}$ & $\stackrel{\sim}{\rightarrow}$ & $\stackrel{\stackrel{\rho}{\sim}}{\sim}$ & $\stackrel{\infty}{\stackrel{\infty}{\varrho}}$ & & $\begin{array}{l}n \\
\mathfrak{y} \\
z\end{array}$ & $\stackrel{\infty}{\varrho}$ & 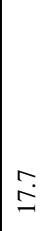 & $\therefore$ & 3 & $\stackrel{\stackrel{i}{\mathrm{i}}}{ }$ & $\begin{array}{c}\hat{\sigma} \\
\stackrel{\infty}{\infty} \\
\frac{1}{1} \\
\tilde{d} \\
d \\
\tilde{d} \\
\tilde{\infty} \\
\infty\end{array}$ & 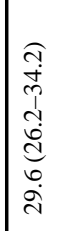 & 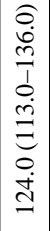 & 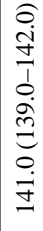 \\
\hline & 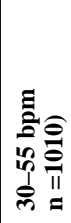 & 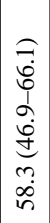 & $n$ & min & S & $\begin{array}{l}\infty \\
\stackrel{\infty}{i}\end{array}$ & فْ & : & $\hat{\dot{m}}$ & $\stackrel{m}{m}$ & $\stackrel{\vec{a}}{\overrightarrow{\mathrm{a}}}$ & & $\stackrel{n}{+}$ & $\stackrel{\infty}{a}$ & 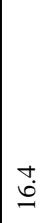 & $\mid \begin{array}{l}0 \\
1\end{array}$ & $\stackrel{\infty}{\infty}$ & $\hat{\ddot{\theta}}$ & 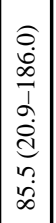 & 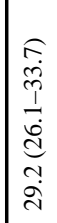 & 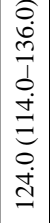 & $\begin{array}{l}\text { di } \\
\frac{1}{d} \\
\stackrel{j}{d}\end{array}$ \\
\hline
\end{tabular}

를

흄

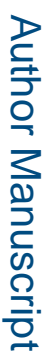

$\frac{0}{0}$
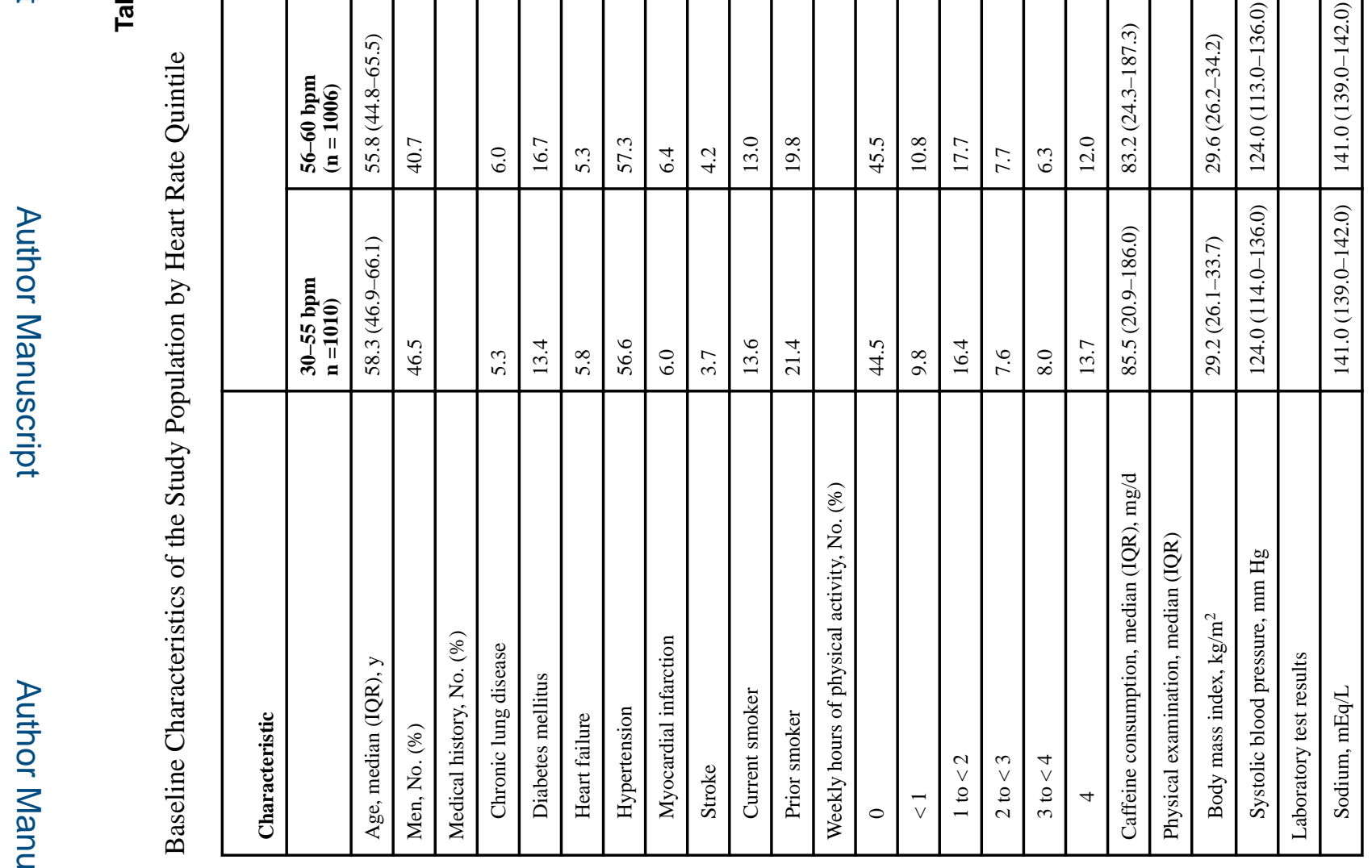

로을

JAMA Cardiol. Author manuscript; available in PMC 2017 February 16. 


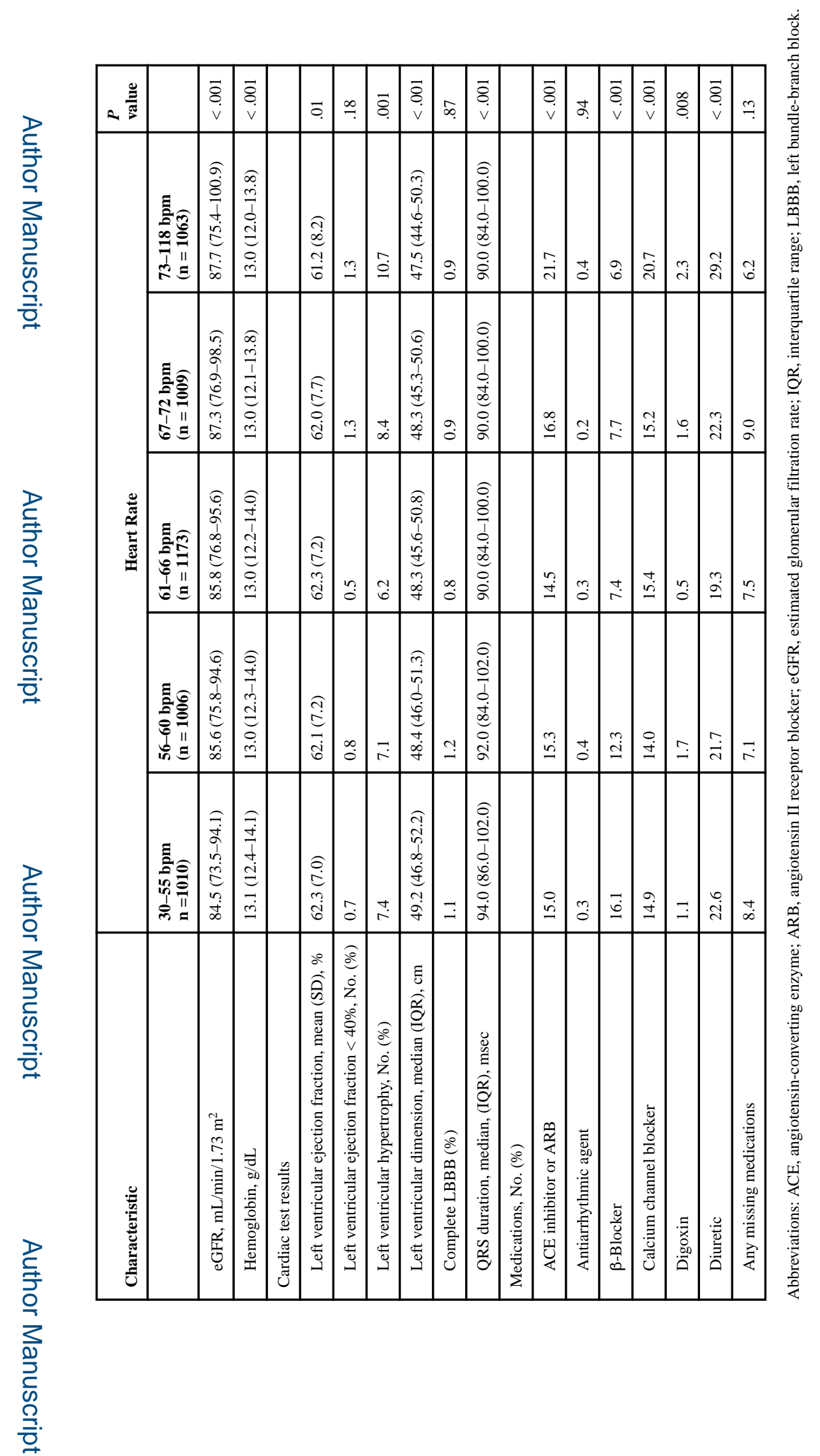

JAMA Cardiol. Author manuscript; available in PMC 2017 February 16. 
Table 2

Risk for 9-Year All-Cause Mortality and 7-Year Heart Failure Hospitalization With Increased Heart Rate

\begin{tabular}{|c|c|c|c|c|}
\hline Outcome & $\begin{array}{l}\text { Unadjusted HR } \\
\text { (95\% CI) }\end{array}$ & $\begin{array}{l}P \\
\text { Value }\end{array}$ & $\begin{array}{l}\text { Adjusted HR } \\
(95 \% \text { CI })^{a}\end{array}$ & $\begin{array}{l}P \\
\text { Value }\end{array}$ \\
\hline \multicolumn{5}{|l|}{ All-cause mortality } \\
\hline $30-55 \mathrm{bpm}$ & $1.00[$ Reference $]$ & & 1.00 [Reference] & \\
\hline $56-60 \mathrm{bpm}$ & $1.12(0.83-1.53)$ & .45 & $1.29(0.95-1.76)$ & .11 \\
\hline $61-66 \mathrm{bpm}$ & $1.12(0.83-1.50)$ & .46 & $1.50(1.10-2.04)$ & .01 \\
\hline $67-72 \mathrm{bpm}$ & $1.11(0.82-1.51)$ & .50 & $1.42(1.03-1.95)$ & .03 \\
\hline $73-118 \mathrm{bpm}$ & $2.10(1.60-2.76)$ & $<.001$ & $2.38(1.78-3.19)$ & $<.001$ \\
\hline Baseline heart rate per $5 \mathrm{bpm}$ increase & $1.14(1.10-1.19)$ & $<.001$ & $1.14(1.10-1.19)$ & $<.001$ \\
\hline \multicolumn{5}{|l|}{ Heart failure hospitalization } \\
\hline $30-55 \mathrm{bpm}$ & $1.00[$ Reference $]$ & & 1.00 [Reference] & \\
\hline $56-60 \mathrm{bpm}$ & $1.13(0.78-1.65)$ & .52 & $1.22(0.83-1.79)$ & .31 \\
\hline $61-66$ bpm & $1.11(0.77-1.59)$ & .59 & $1.34(0.92-1.96)$ & .13 \\
\hline $67-72 \mathrm{bpm}$ & $1.12(0.77-1.63)$ & .55 & $1.19(0.80-1.76)$ & .39 \\
\hline $73-118$ bpm & $1.95(1.39-2.73)$ & $<.001$ & $1.79(1.25-2.58)$ & .002 \\
\hline Baseline heart rate per $5 \mathrm{bpm}$ increase & $1.14(1.09-1.20)$ & $<.001$ & $1.10(1.05-1.16)$ & $<.001$ \\
\hline
\end{tabular}

Abbreviation: HR, hazard ratio.

${ }^{a}$ Adjusted for age, sex, prior myocardial infarction, heart failure, hypertension, stroke, diabetes mellitus, lung disease, current smoking, prior smoking, alcoholic drinks/week, physical activity hours/week, caffeine mg/day, body mass index, neck circumference, systolic blood pressure, sodium, estimated glomerular filtration rate, hemoglobin, ejection fraction, left ventricular hypertrophy, left ventricular dimension, left bundle branch block, right bundle branch block, QRS duration, angiotensin-converting enzyme inhibitor or angiotensin II receptor blocker, antiarrhythmic agent, antiplatelet agent, $\beta$-blocker, calcium channel blocker, digoxin, diuretic, and statin. 
Table 3

Participant Characteristics Associated With Increased Heart Rate Greater Than 5 bpm

\begin{tabular}{|c|c|c|c|c|}
\hline Variable & $\begin{array}{l}\text { Unadjusted RR } \\
(95 \% \text { CI })\end{array}$ & $\begin{array}{l}P \\
\text { Value }\end{array}$ & $\begin{array}{l}\text { Adjusted RR } \\
\text { (95\% CI) }\end{array}$ & $\begin{array}{l}P \\
\text { Value }\end{array}$ \\
\hline Age per 5 years & $1.02(0.99-1.04)$ & .16 & $0.99(0.96-1.02)$ & .54 \\
\hline Men & $1.18(1.06-1.31)$ & .003 & $0.92(0.77-1.11)$ & .39 \\
\hline \multicolumn{5}{|l|}{ Medical history } \\
\hline Myocardial infarction & $1.31(1.04-1.64)$ & .02 & $1.15(0.91-1.45)$ & .25 \\
\hline Heart failure & $1.05(0.85-1.30)$ & .67 & $0.97(0.76-1.23)$ & .77 \\
\hline Hypertension & $1.03(0.92-1.15)$ & .61 & $0.98(0.85-1.13)$ & .78 \\
\hline Stroke & $1.04(0.76-1.42)$ & .80 & $0.96(0.72-1.28)$ & .77 \\
\hline Diabetes & $1.21(1.06-1.37)$ & .004 & $1.38(1.20-1.59)$ & $<.001$ \\
\hline Chronic lung disease & $1.00(0.80-1.24)$ & .99 & $1.04(0.84-1.29)$ & .70 \\
\hline Current smoker & $1.30(1.12-1.51)$ & $<.001$ & $1.32(1.12-1.55)$ & $<.001$ \\
\hline Prior smoker & $1.13(0.99-1.29)$ & .08 & $1.09(0.95-1.24)$ & .24 \\
\hline Average drinks per week in prior year & $1.01(1.00-1.01)$ & .08 & $1.00(1.00-1.01)$ & .33 \\
\hline \multicolumn{5}{|l|}{ Weekly mean hours of physical activity } \\
\hline 0 & 1.00 [Reference] & & $1.00[$ Reference $]$ & \\
\hline$<1$ & $0.99(0.83-1.19)$ & .95 & $1.03(0.87-1.23)$ & .72 \\
\hline 1 to $<2$ & $0.99(0.85-1.15)$ & .90 & $0.99(0.85-1.15)$ & .88 \\
\hline 2 to $<3$ & $0.92(0.74-1.13)$ & .41 & $0.91(0.75-1.12)$ & .38 \\
\hline 3 to $<4$ & $0.89(0.70-1.12)$ & .32 & $0.84(0.67-1.06)$ & .14 \\
\hline$\geq 4$ & $0.97(0.81-1.16)$ & .74 & $0.94(0.79-1.11)$ & .45 \\
\hline Caffeine consumption per $50 \mathrm{mg} /$ day & $0.99(0.97-1.00)$ & .11 & $0.98(0.97-1.00)$ & .02 \\
\hline \multicolumn{5}{|l|}{ Physical examination } \\
\hline Body mass index per $1 \mathrm{~kg} / \mathrm{m}^{2}$ & $1.00(0.99-1.00)$ & .42 & $1.00(0.99-1.01)$ & .66 \\
\hline Neck circumference per $1 \mathrm{~cm}$ & $1.02(1.00-1.03)$ & .03 & $1.03(1.01-1.05)$ & .02 \\
\hline Systolic blood pressure per $5 \mathrm{~mm} \mathrm{Hg}$ & $1.00(0.98-1.01)$ & .86 & $1.00(0.98-1.01)$ & .68 \\
\hline \multicolumn{5}{|l|}{ Laboratory test results } \\
\hline Sodium per $1 \mathrm{mEq} / \mathrm{L}$ & $1.00(0.98-1.03)$ & .89 & $1.00(0.97-1.02)$ & .89 \\
\hline eGFR per $5 \mathrm{~mL} / \mathrm{min} / 1.73 \mathrm{~m}^{2}$ & $1.00(0.98-1.02)$ & .97 & $1.02(1.00-1.04)$ & .08 \\
\hline Hemoglobin per $1 \mathrm{~g} / \mathrm{dL}$ & $1.04(1.00-1.08)$ & .06 & $0.99(0.95-1.04)$ & .76 \\
\hline \multicolumn{5}{|l|}{ Cardiac test results } \\
\hline Ejection fraction per 5\% decrease & $1.02(0.98-1.06)$ & .45 & $1.04(1.00-1.08)$ & .06 \\
\hline Left ventricular hypertrophy & $1.10(0.90-1.34)$ & .35 & $1.10(0.89-1.35)$ & .38 \\
\hline Left ventricular dimension per $1 \mathrm{~cm}$ & $1.01(1.00-1.03)$ & .02 & $0.99(0.98-1.01)$ & .22 \\
\hline Complete LBBB & $1.88(1.21-2.92)$ & .005 & $2.11(1.23-3.63)$ & .007 \\
\hline Complete RBBB & $1.12(0.67-1.87)$ & .65 & $1.33(0.76-2.32)$ & .32 \\
\hline QRS duration per $5 \mathrm{msec}$ & $1.02(1.00-1.04)$ & .11 & $0.98(0.95-1.00)$ & .08 \\
\hline Baseline heart rate per $5 \mathrm{bpm}$ & $0.79(0.77-0.81)$ & $<.001$ & $0.77(0.75-0.79)$ & $<.001$ \\
\hline
\end{tabular}




\begin{tabular}{|l|l|l|l|l|}
\hline Variable & $\begin{array}{l}\text { Unadjusted RR } \\
\mathbf{9 5 \%} \mathbf{C I})\end{array}$ & $\begin{array}{l}\boldsymbol{P} \\
\text { Value }\end{array}$ & $\begin{array}{l}\text { Adjusted RR } \\
\mathbf{9 5 \%} \mathbf{C I})\end{array}$ & $\begin{array}{l}\boldsymbol{P} \\
\text { Value }\end{array}$ \\
\hline Medications & & & & \\
\hline ACE inhibitor or ARB & $1.11(0.95-1.28)$ & .18 & $1.03(0.87-1.20)$ & .76 \\
\hline Antiarrhythmic agent & $0.63(0.12-3.40)$ & .59 & $0.97(0.15-6.28)$ & .98 \\
\hline Antiplatelet agent & $0.95(0.57-1.60)$ & .86 & $0.93(0.53-1.61)$ & .79 \\
\hline$\beta$-Blocker & $1.25(1.06-1.47)$ & .008 & $0.91(0.76-1.09)$ & .30 \\
\hline Calcium channel blocker & $1.08(0.94-1.25)$ & .29 & $1.10(0.95-1.28)$ & .22 \\
\hline Digoxin & $1.16(0.67-2.00)$ & .59 & $0.96(0.56-1.65)$ & .90 \\
\hline Diuretic & $1.08(0.95-1.23)$ & .23 & $1.11(0.95-1.30)$ & .18 \\
\hline Statin & $1.08(0.91-1.28)$ & .37 & $0.94(0.79-1.13)$ & .52 \\
\hline Any missing medications & $1.22(1.01-1.47)$ & .04 & $1.14(0.95-1.37)$ & .16 \\
\hline
\end{tabular}

Abbreviations: ACE, angiotensin-converting enzyme; ARB, angiotensin II receptor blocker; eGFR, estimated glomerular filtration rate; LBBB, left bundle-branch block; RBBB, right bundle-branch block; RR, risk ratio. 